\title{
EXISTENCE RESULTS FOR NON-INSTANTANEOUS IMPULSIVE FRACTIONAL FUNCTIONAL DIFFERENTIAL EQUATION WITH INFINITE DELAY
}

\section{JAYANTA BORAH* AND SWAROOP NANDAN BORA}

\begin{abstract}
In this article, we investigate the existence of mild solution of a class of impulsive fractional functional differential equations with infinite delay in a Banach space. By employing fractional calculus and fixed point theorems, the results are obtained under the assumption that the linear part of the equations generates a compact analytic semigroup.
\end{abstract}

Mathematics subject classification (2020): 26A33, 34A08, 35R12.

point theorem.

Keywords and phrases: Fractional evolution equation, mild solution, non-instantaneous impulse, fixed

\section{REFERENCES}

[1] A. Boudaoui, T. Caraballo And A. Ouhab, Stochastic differential equation with noninstantaneous impulses driven by fractional Brownian motion, Discrete and Continuous Dynamical Systems-series B. 22 (7) (2017), 2521-2541.

[2] J. BORAH AND S. N. BORA, Existence of mild-solution for mixed Volterra-Fredholm integro fractional differential equation with non-instantaneous impulses, Differential Equations and Dynamical Systems (2018) 1-12.

[3] Y. K. Chang, A. Anguraj And M. M. Arjunan, Existence results for impulsive neutral functional differential equations with infinite delay, Nonlinear Analalysis: Hybrid System 2 (2008), 209_ 218.

[4] P. Chen, X. Zhang And Y. LI, Existence of mild-solutions to partial differential equations with non-instantaneous impulses, Electronic Journal of Differential Equations 241 (2016), 1-11.

[5] G. R. GAUTAM AND J. DABAS, Mild-solutions for class of neutral fractional functional differential equations with not instantaneous impulses, Applied Mathematics and Computation 259 (2015), 480489.

[6] J. K. Hale And J. Kato, Phase space for retarded equations with infinite delay, Funkcial. Ekvac. 21 (1) (1978), 11-41.

[7] P. Kumar, D. N. Pandey And D. Bahuguna, On a new class of abstract impulsive functional differential equations of fractional order, Journal of Nonlinear Science and Applications 72 (2014), $102-114$.

[8] E. HeRnÁndez And D. O'Regan, On a new class of abstract impulsive differential equations, Proceeding of American Mathematical Society 141 (5) (2013), 1641-1649.

[9] L. HU, Y. REN AND R. SAKTHIVEL, Existence and uniqueness of mild solutions for semilinear integro-differential equations of fractional order with nonlocal initial conditions and delay, Semigroup Forum 793 (2009), 507-514.

[10] A. A. Kilbas, H. M. SRivastava and J. J. Trujillo, Theory and Applications of Fractional Differential Equations, North Holland Mathematics Studies, Elsevier Science Inc., New York, 204 (2006).

[11] N. I. Mahmudov AND S. Zorlou, On the approximate controllability of fractional evolution equations with compact analytic semigroup, Journal of Computational and Applied Mathematics 259 (2014) 194-204. 
[12] G. M. Mophou, G. M. N'GuÉRÉKATA, Existence of the mild solution for some fractional differential equations with nonlocal conditions, Semigroup Forum, 79 (2009) 315-322.

[13] A. PAZY, Semigroups of Linear Operators and Applications to Partial Differential Equations, SpingerVerlag, New York (1983).

[14] M. PierRi, D. O'RegAn AND V. Rolnik, Existence of solutions for semi-linear abstract differential equations with not instantaneous impulses, Applied Mathematics and Computation 21912 (2013), 6743-6749.

[15] M. Pierri, H. R. Hennriquez and A. Prokopczyk, Global solutions of abstract differential equations with non-instantaneous impulse, Mediterranean Journal of Mathematics 13 (4) (2016), 1685-1708.

[16] I. Podulbny, Fractional Differential Equations: An introduction to fractional derivatives, fractional differential equations, to methods of their solution and some of their applications, Academic Press, San Diego, (1998).

[17] Z. TAI AND X. WANG, Controllability of fractional order impulsive neutral functional infinite delay integro differential systems in Banach space, Appl. Math. Letters 2211 (2009), 1760-1765.

[18] J. WANG AND X. LI, Periodic boundary value problem for integer/fractional order differential equations with not-instantaneous impulse, Applied Mathematics and Computing 46 1-2 (2014), 321-334.

[19] J. WANG AND Y. ZHOU, A class of fractional evolution equations and optimal controls, Nonlinear Analysis: Real World Applications 121 (2011), 262-272.

[20] L. Zhang AND Y. ZHOU, Fractional Cauchy problems with almost sectorial operators, Applied Mathematics and Computations 257 (2015), 145-157.

[21] Y. Zhou, W. Jinrong And Z. Lu, Basic Theory of Fractional Differential equations, World Scientific (2016).

[22] Y. ZHOU AND F. JiAO, Existence of mild solutions for fractional neutral evolution equations, Computers and Mathematics with Applications, 59, 3 (2010), 1063-1077. 